\title{
Variation of Transition Temperatures from Upper to Lower Bainites in Plain Carbon Steels
}

\author{
M. Oka and H. Okamoto \\ Department of Mechanical Engineering, Tottori University, Tottori 680, Japan
}

\begin{abstract}
Experimental results and explanations for the transition temperature from upper to lower bainites in carbon steels containing from 0.20 to $1.80 \mathrm{wt} \% \mathrm{C}$ were presented metallographically and kinematically. The experimental results are summarized as follows: 1) Lower bainite is not formed in steels with less than 0.35 wt\% $\mathrm{C}$ and no transition from upper to lower bainite occurs. 2) The transition temperature of steels containing from 0.54 to 1.10 $\% \mathrm{C}$ indicates a constant temperature of $350^{\circ} \mathrm{C}$ and does not depend on the carbon content. It is important to note that a transition temperature of $350^{\circ} \mathrm{C}$ corresponds to the Ms temperature of a $0.55 \% \mathrm{C}$ steel being the boundary of the martensite morphology between a lath and a plate. 3) Transition temperatures of steels with more than $1.10 \% \mathrm{C}$ decrease along the a line below about $65^{\circ} \mathrm{C}$ from $\mathrm{T}_{0}$-composition line. The bainitic transformation is essentially a kind of the martensitic one and its nucleation site is considered to be a carbon depleted zone in austenite by the thermal fluctuation of carbon atom at an isothermal holding temperature. The supercooling of about $65^{\circ} \mathrm{C}$ below the $\mathrm{T}_{0}$-composition line at the carbon range more than $1.10 \mathrm{wt} \% \mathrm{C}$ is attributed to the non-chemical free energy for the displacive growth of lower bainite.
\end{abstract}

\section{INTRODUCTION}

It is well known from the optical microscopic scale that there are two types of bainites in plain carbon steels, a feathery upper bainite and a needle-like lower bainite. The overall kinetics of bainite transformations have been investigated by the dilatometry and electrical resistivity measurements[1]. According to them, a drastic change of overall activation energy occurred at about $350^{\circ} \mathrm{C}$ and it corresponded to a microstructural change from a feathery to a needle one in medium and high carbon steels.

Meanwhile, with the application of electron microscopy to the microstructural examination of bainite, two distinct classifications have been presented. The first is that bainitic ferrites without and with carbides are classified as upper bainite(UB) and lower bainite(LB), respectively. Based on the above classification, Pickering[2] reported that transition temperatures between UB and LB were a nearly constant of $350^{\circ} \mathrm{C}$ in 0.7 and $1.0 \mathrm{wt} \% \mathrm{C}$ steels, but they laid between 450 and $550^{\circ} \mathrm{C}$ in the carbon range from 0.1 to $0.6 \mathrm{wt} \%$. The second is that UB and LB are characterized by the shapes of bainitic ferrites, that is, lath-like and plate-like, respectively. This was suggested by Ohmori and Honeycombe[3].

Several works on the transition temperatures between $\mathrm{UB}$ and $\mathrm{LB}$ have been reported so far, but there are no reports on plain carbon steels containing from 0.2 to $1.8 \mathrm{wt} \% \mathrm{C}$ consistently. The measurement of transition temperatures between $\mathrm{UB}$ and $\mathrm{LB}$ is considered to be significant for realizing the transformation mechanisms of two types of bainites.

The purposes of this paper are to measure the transition temperatures in steels $(0.2-1.8 \mathrm{wt} \% \mathrm{C})$ by means of kinematical and metallographic methods and to describe the reason why the transition occurs from UB to LB.

\section{EXPERIMENTAL PROCEDURE}

Four hypoeutectoid commercial plain carbon steels and six hypereutectoid high purity $\mathrm{Fe}-\mathrm{C}$ steels induction melted were employed in this investigation. The compositions and their Ms temperatures of all steels used are listed in Table 1.

Sheet specimens $17 \times 12 \mathrm{~mm}$ and $1 \mathrm{~mm}$ thick were austenitized at $1100^{\circ} \mathrm{C}$ for $10 \mathrm{~min}$ (at $1150^{\circ} \mathrm{C}$ for 
Table 1. Steel compositions $(w t \%)$ and $\mathrm{Ms}$ temperatures $\left({ }^{\circ} \mathrm{C}\right)$ of steels used

\begin{tabular}{ccccccc}
\hline No. & C & Si & Mn & P & S & Ms \\
\hline 1 & 0.20 & 0.21 & 0.42 & 0.014 & 0.017 & 464 \\
2 & 0.36 & 0.21 & 0.71 & 0.014 & 0.020 & 395 \\
3 & 0.54 & 0.18 & 0.79 & 0.021 & 0.015 & 326 \\
4 & 0.69 & 0.23 & 0.90 & 0.015 & 0.013 & 272 \\
5 & 0.85 & 0.027 & 0.01 & -- & -- & 250 \\
6 & 1.10 & 0.01 & tr & 0.006 & 0.006 & 175 \\
7 & 1.28 & 0.00 & 0.01 & 0.006 & 0.002 & 126 \\
8 & 1.45 & 0.02 & tr & 0.005 & 0.005 & 100 \\
9 & 1.66 & 0.00 & 0.01 & 0.006 & 0.004 & 76 \\
10 & 1.80 & 0.05 & 0.01 & 0.003 & 0.011 & 73 \\
\hline
\end{tabular}

$15 \mathrm{~min}$ ) for hypoeutectoid (hypereutectoid) steels under a dynamically evacuated condition. Then the specimens were plunged into a salt bath, partially transformed isothermally at temperatures between 450 and $200^{\circ} \mathrm{C}$, and finally quenched into water to suppress the further isothermal transformation. The specimens were etched in 2\% Nital etchant. Both optical and SEM microscopies were used to observe the morphology of bainites. The temperature at which the feathery morphology was replaced by the needle one was determined as the "microstructural transition temperature". Two planes perpendicular to each other of some specimens were polished and etched, and the planes were observed simultaneously by using the long depth of a focus in SEM to observe three-dimensional morphology of bainites. The temperature at which the lath morphology was replaced by the plate one was also used to determine the microstructural transition temperature.

Specimens for dilatometry, with $40 \mathrm{~mm}$ long and $1 \mathrm{~mm}^{2}$ in cross section, were machined. They were austenitized in the same way as that of the metallographic specimens, and then rapidly plunged into a salt bath, mounted in a dilatometer, and the overall transformation rates were followed by a conventional push-rod type dilatometer. The "kinetic transition temperature" was determined from the Arrhenius plot (logarithmic time for $50 \%$ transition vs. $1 / \mathrm{T}$ ).

\section{RESULTS}

Figure 1 shows Arrhenius plots for $0.54,0.69$ and $1.10 \mathrm{wt} \% \mathrm{C}$ steels. Marked changes in kinetics of decomposition of austenite were observed around $350^{\circ} \mathrm{C}$ in three steels and they were in agreement with published data. These results were also confirmed by optical micrographs as shown in Figure 2. Figures 2(a) and (c) show the feathery UB formed at $400^{\circ} \mathrm{C}$ in 0.36 and $0.85 \mathrm{wt} \% \mathrm{C}$ steels, respectively, and Figures 2 (b) and (d) show the needle-like LB formed at $350^{\circ} \mathrm{C}$ in the same steels, respectively. It is to be noted that the feathery UB coexists with the needle-like $\mathrm{LB}$ in (d). No LB was observed in a $0.20 \mathrm{wt} \% \mathrm{C}$ steel, because its Ms temperature is higher than $350^{\circ} \mathrm{C}$.

Figure 3 shows Arrhenius plots for 1.28, 1.45 and $1.66 \mathrm{wt} \% \mathrm{C}$ steels and indicates that their kinematical transition temperatures are 313, 266 and $236^{\circ} \mathrm{C}$, respectively. It is clear that transition temperatures decrease with increasing the carbon content from 1.28 to $1.66 \mathrm{wt} \% \mathrm{C}$. The above results were also confirmed by optical micrography, as shown in Figure 4. Figures 4(a), (c), (e), and (g) in the left column are optical micrographs showing the lowest temperatures at which the nodular and feathery type UB's occur for each steel of 1.28, 1.451 .66 and $1.80 \mathrm{wt} \% \mathrm{C}$, respectively.

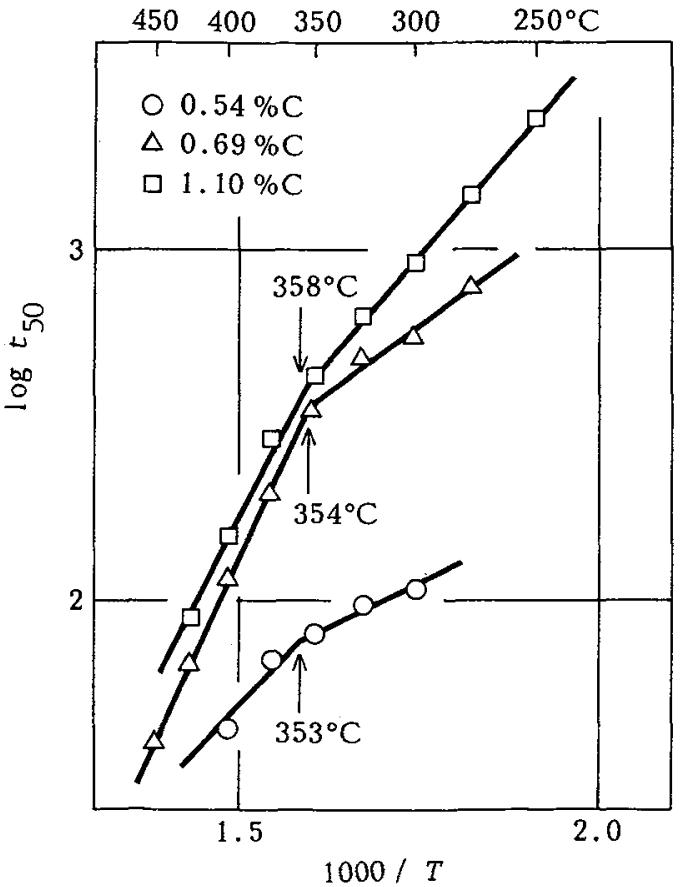

Figure 1. Arrhenius plots of the reaction data for $0.54,0.69$ and $1.10 \mathrm{wt} \% \mathrm{C}$ Steels. 

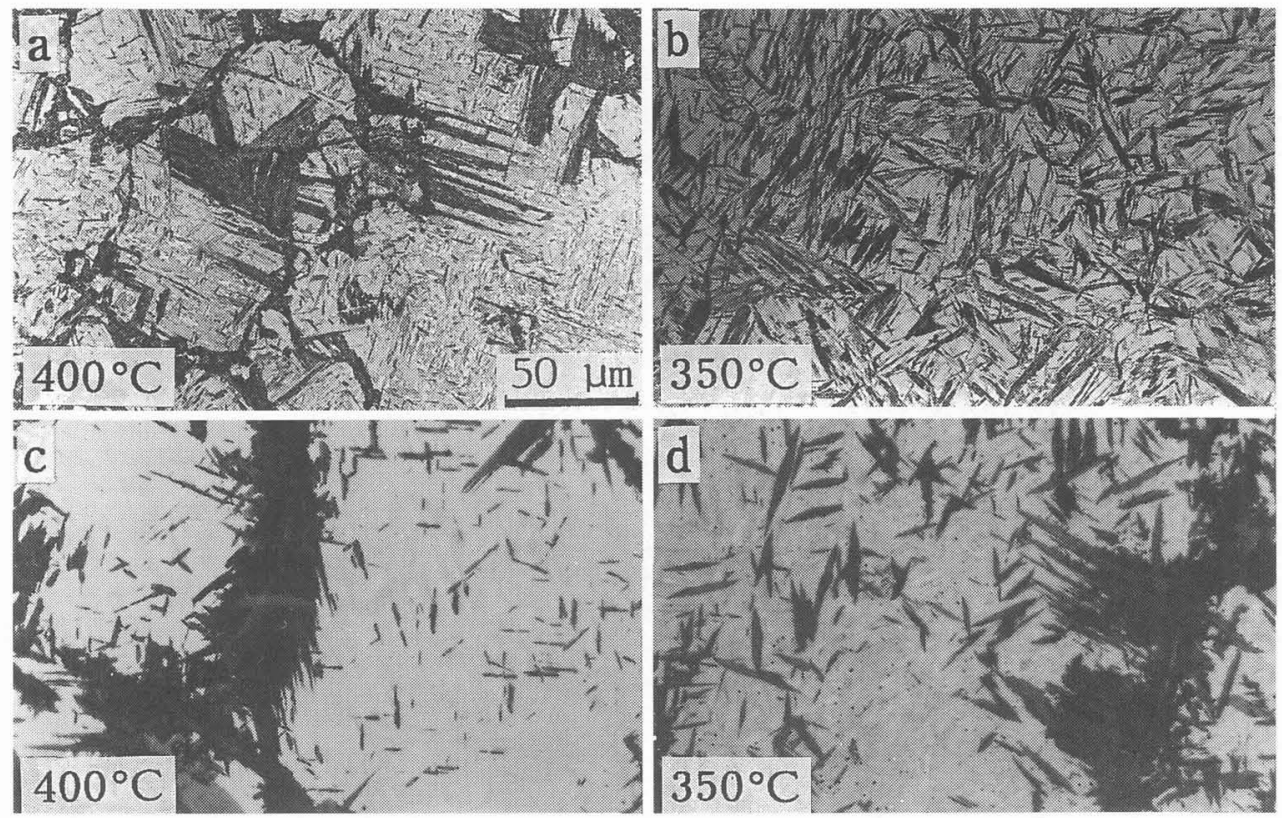

Figure 2. Optical micrographs showing UB and LB formed at 400 and $350^{\circ} \mathrm{C}$ in $0.36 \mathrm{wt} \% \mathrm{C}$ (a)-(b), and $0.85 \mathrm{wt} \% \mathrm{C}$ steels (c)-(d), respectively. $2 \%$ Nital etched.

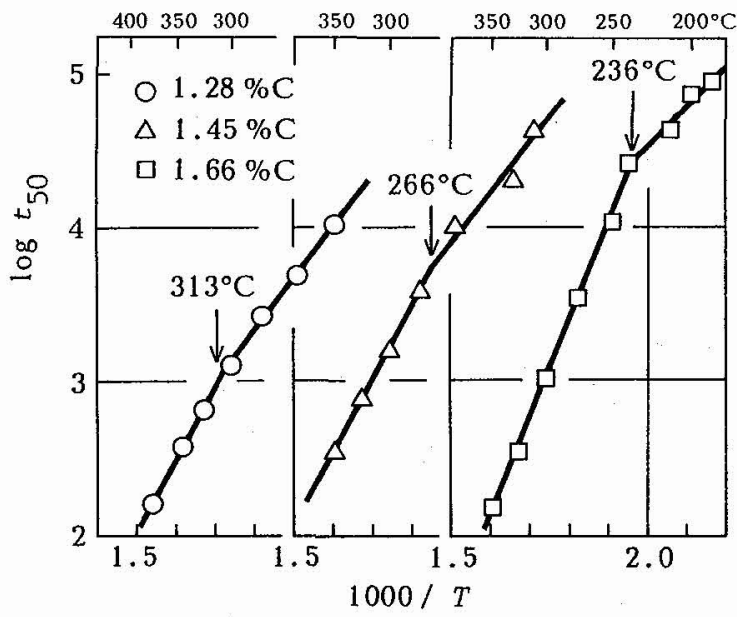

Figure 3. Arrhenius plots of the reaction data for $1.28,1.45$ and $1.66 \mathrm{wt} \% \mathrm{C}$ steels.

On the other hand, Figures 4(b), (d), (f) and (h) in the right column are micrographs showing the high temperatures at which the lenticular and plate-like LB can be seen for each steel of four stecls. It is to be noted that the abrupt change in morphology occurs even at the interval of $50^{\circ} \mathrm{C}$.

Figure 5 shows the summary of kinematical and metallographical results as "morphology map of UB and $L B^{\prime \prime}$. The $T_{0}$ versus composition curve was calculated by the regular solution model[4]. As indicated in Figure 5, it can be seen that the transition temperatures are a constant of $350^{\circ} \mathrm{C}$ in the range from 0.54 

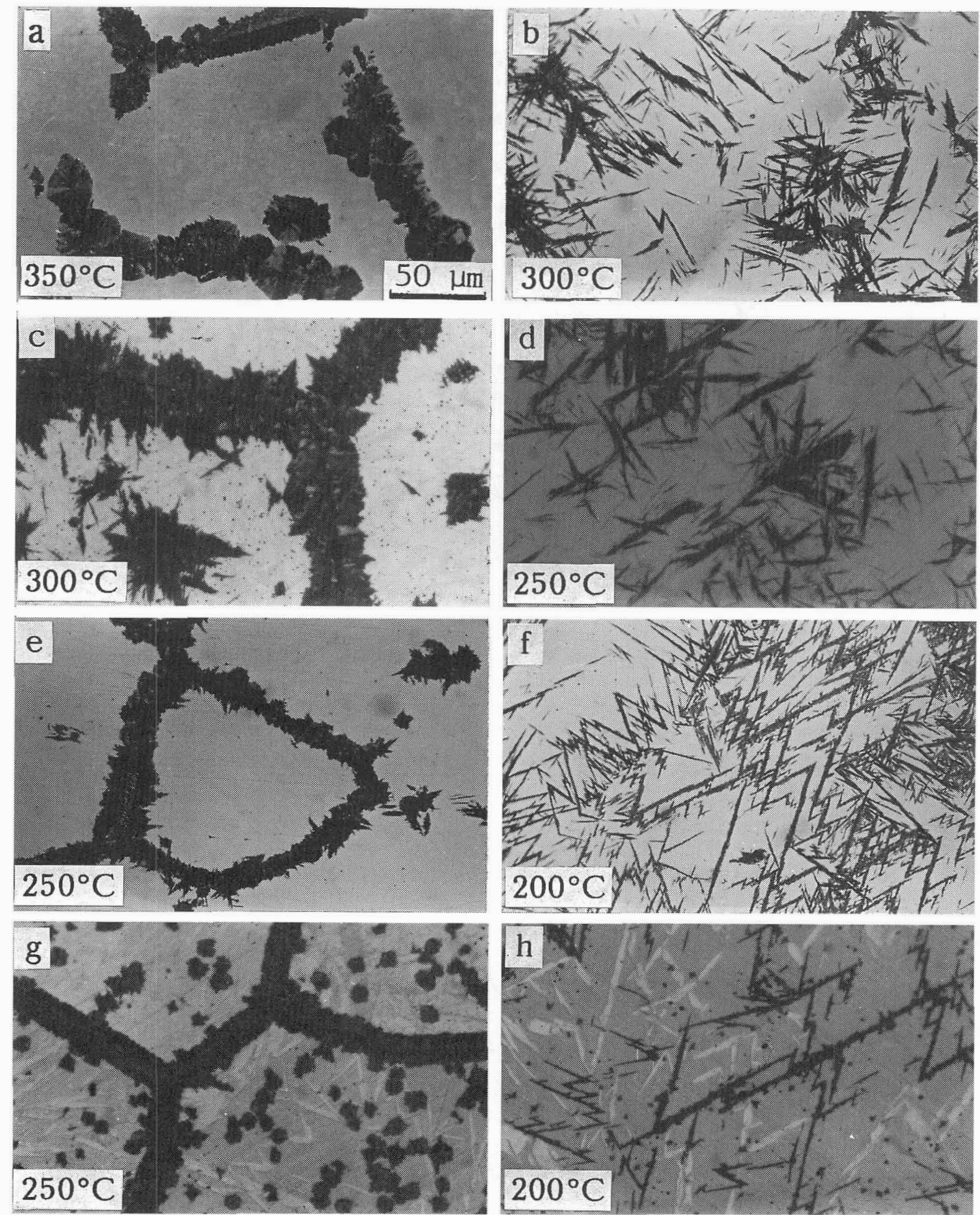

Figure 4. Optical micrographs showing UB and LB formed at transition temperatures indicated in Figure. $2 \%$ Nital etched. (a)-(b), 1.28 wt\%C; (c)-(d), 1.45 wt\%C; (e)-(f), 1.66 wt\%C; (g)-(h), 1.80 wt\%C. 


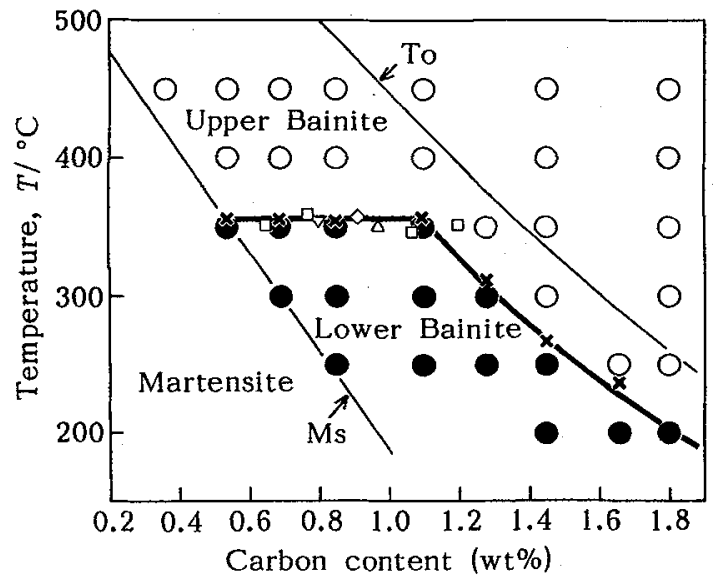

Figure 5. A morphology map showing temperature-composition regions where $\mathrm{UB}(O)$ and LB( $O$ ) were observed in this study. Transition temperatures determined kinematically are also indicated by present results $(x)$.

to $1.10 \mathrm{wt} \% \mathrm{C}$, but decrease with increasing the carbon content containing more than $1.10 \mathrm{wt} \%$ along a line being below $65^{\circ} \mathrm{C}$ from $\mathrm{T}_{0}$ line.

\section{DISCUSSION}

It is well known that the morphology of martensites depends on the carbon content and the critical carbon content at which the martensite morphology changes from a needle or a plate to a feathery or a lath type is about $0.5 \mathrm{wt} \% \mathrm{C}\left(\mathrm{Ms}=350^{\circ} \mathrm{C}\right.$ ). The terminology of "feathery and needle" is used for UB and LB from a light microscopic scale, respectively and the one of "lath and plate" is used from an electron microscopic scale.

The morphology of bainites (UB and LB) in plain carbon steels varies with the formation temperatures and carbon concentration. Tsuzaki at al.[5] presented a new proposal of the formation of bainite as follows. Carbon atoms play an important role in the nucleation process of the bainite reaction; the formation of the carbon depleted zone in the austenite state as a result of statistical fluctuation of carbon concentration assists the martensitic nucleation of bainitic ferrite from austenite at the carbon concentration of a Ms temperature. This Ms corresponds to an isothermal holding temperature for the bainite formation. Once the nucleation occurs, the bainitic ferrite can grow martensitically into the surrounding austenite with the average carbon content. Their proposal has been accepted in the present study.

From the morphological similarity between bainite and martensite, a new interpretation for the formation of UB and LB in steels containing less than $0.8 \mathrm{wt} \% \mathrm{C}$ i.e., eutectoid component, is presented here. "If the carbon concentration at the nucleation site of bainite is the same as that corresponding to the formation of the lath martensite, UB i.e., feathery or lath type bainite, is formed at temperatures above $350^{\circ} \mathrm{C}$. If it is as high as that for the formation of the plate martensite, LB i.e., needle or plate type bainite is formed at temperature below $350^{\circ} \mathrm{C} . "$

The morphology of UB in steels containing more than $1.10 \mathrm{wt} \% \mathrm{C}$ changed from a feathery type to a nodular one. This change of UB were already discussed[6,7]. The reason why the transition temperatures in the above steels decreased along a line being below $65^{\circ} \mathrm{C}$ from $\mathrm{T}_{0}$, as shown in Figure 5 , is considered that LB essentially forms in a displacive manner. Therefore, they are not able to cross the $T_{0}$ line. That is, $\mathrm{LB}$ does not form at temperatures above $\mathrm{T}_{0}$.

The supercooling of about $65^{\circ} \mathrm{C}$ below $\mathrm{T}_{0}$ at the range $(1.10-1.80 \mathrm{wt} \% \mathrm{C})$ is also considered to the non-chemical free energy for the displacive growth of LB. The discussion on this point will appear elsewhere, because of limited space in this paper. 


\section{CONCLUSIONS}

Experimental results and explanations for the transition temperature from upper to lower bainites in carbon steels containing from 0.20 to $1.80 \mathrm{wt} \% \mathrm{C}$ was presented metallographically and kinematically. The experimental results were summarized as follows:

1). Lower bainite is not formed in steels with less than $0.35 \mathrm{wt} \% \mathrm{C}$ and no transition from upper to lower bainite occurs.

2) The transition temperature of steels containing from 0.54 to $1.10 \% \mathrm{C}$ indicates a constant temperature of $350^{\circ} \mathrm{C}$ and does not depend on the carbon content. It is important to note that a transition temperature of $350^{\circ} \mathrm{C}$ corresponds to the Ms temperature of a $0.55 \% \mathrm{C}$ steel being the boundary of the martensite morphology between a lath and a needle (or plate) type.

3) Transition temperatures of stecls containing more than $1.10 \% \mathrm{C}$ decrease along the $\mathrm{T}_{0}$-composition line by about $65^{\circ} \mathrm{C}$.

The bainitic transformation is essentially martensitic and its nucleation site is considered to be a carbon depleted zone in austenite created by the thermal fluctuation of carbon atom at an isothermal holding temperature.

The supercooling of about $65^{\circ} \mathrm{C}$ below the $\mathrm{T}_{0}$-composition line at the carbon range more than 1.10 $\mathrm{wt} \% \mathrm{C}$ is attributed to the non-chemical free energy for the displacive growth of lower bainite.

\section{References}

[1] Radcliffe S.V. and Rollason E.C., J.Iron \& Steel Inst. 191(1959)56-66.

[2] Pickering,F.B., Transformation and Hardenability in Stecls, Climax Molybdenum (Ann Arbor, MI 1967)pp.109-132.

[3] Ohmori Y. and Honeycombe R.W.K., Trans. ISIJ 11(1971)1160-1164.

[4] Nishizawa T., Bull. of JIM 12(1973)321-325.

[5] Tsuzaki K., Fujiwara K. and Maki T., Mater. Trans. JIM 32(1991)667-678.

[6] Okamoto H. and Oka M., Mater. Sci. Forum 56-58(1990)287-292.

[7] Spanos G., Fang H.S., Sarma D.S. and Aaronson H.I., Metall. Trans. 21A(1990)1391-1411. 